\title{
Political Commitment and Sense of Social Responsibility among Social Entrepreneurs in Davao City, Philippines
}

\author{
Chrisbelt A. Medina ${ }^{1}$, Febbie Miya T. Maiz ${ }^{1}$, Joepet P.Somosot ${ }^{1}, \&$ Rico B. Maghuyop, Ed. D. ${ }^{2}$ \\ ${ }^{1}$ Political Science Discipline, University of Mindanao, Davao City, Philippines. \\ ${ }^{2}$ Professional Schools, University of Mindanao, Davao City, Philippines. \\ Correspondence: Rico B. Maghuyop, Professional Schools, University of Mindanao, Davao City, Philippines.
}

Received: January 25, 2016

doi:10.11114/ijsss.v4i4.1450
Accepted: February 14, $2016 \quad$ Available online: March 11, 2016

URL: http://dx.doi.org/10.11114/ijsss.v4i4.1450

\begin{abstract}
Social entrepreneurs can play a game-changing role in local and national development by introducing social innovation. Strongly committed and mission- driven, they employ entrepreneurial schemes to organize and manage resources through financially sound and economically sustainable entities in order to create social value. This study aimed to determine the levels of political commitment and sense of social responsibility among social entrepreneurs of small and medium-sized social enterprises in Davao City. Using the non-experimental descriptive correlation method to gather survey inputs from 47 respondents, the researchers found that the respondents exhibited high levels of political commitment and sense of social responsibility. Furthermore, a significant relationship existed between political commitment and sense of social responsibility. When analyzed according to sex, no significant difference was observed in the level of political commitment. However, a significant difference appeared when analyzed according to type of business venture. No significant difference was ever observed in the level of sense of social responsibility in both variables.
\end{abstract}

Keywords: political commitment, sense of social responsibility, social entrepreneurs, social enterprises, Davao City

\section{Introduction}

\subsection{Background of the Study}

Government resources and state-based mechanisms are not always efficient and effective in delivering quality social services to alleviate the widening economic gap in many developing and underdeveloped countries around the world. As a result, not everyone gets to receive the social services that the government is expected to provide.

In a global climate of uncertainty, there seems to be a growing interest in examining the role of socially-oriented small and medium sized enterprises (SMEs) to complement existing government efforts to remedy some, if not all, of society's problems. In the UK, for example, it has already been an established state policy since the 'New Labour' came to power in 1997 to promote the role of social enterprises in the economy (Spear, Cornforth, \& Aiken, 2009). These so-called small and medium sized social enterprises (SMSEs) have its nascent influence from charity-oriented and volunteer groups. Behind these so-called SMSEs are the social entrepreneurs which are able to effect societal change by means of defining what the social problems are and contextualizing the solutions agenda to solve those problems in innovative ways. Zastrow and Bowker (1984) believed that social problems are defined by assertive groups or individuals claiming that certain social ills affecting society can be solved through collective effort. They further stated that if social entrepreneurs desire a meaningful change to benefit society, they need to have at least the political commitment or political will to pursue those changes. Post, Salmon and Raile (2008) added that with political commitment comes the ability to shape public opinion and influence policymakers either directly or indirectly which would ultimately result to a set of changes within the socio-political and economic system. Equally important as the political commitment is the sense of social responsibility (SSR). In a nutshell, SSR is about shaping a part or a whole of corporate activities to serve societal ends. However, the current thinking on SSR suffers from being less 'socially responsible' than it ought to be. Furthermore, there seems to be little interest given to the SSR-related roles of small businesses as more emphasis is centered on the roles that the big businesses play in eliminating parts of social malaise (Thornton, 2013). 
In the Philippines, SMEs' share of registered business amounts to 99.6\% (Camposano, 2014). However, most SSR-related studies are still typically about large corporations. The development of sense of social responsibility in the Philippines is rooted in the philanthropic tradition of giving and volunteering well observed within and across the kinship groups and even immediate communities. The communitarian nature of Asians in general and Filipinos in particular, is typified in various acts of mutual aid such as the 'bayanihan'. In its early years, SSR was seen only as an accessory to corporate activities. Through time, the concept has evolved into an imperative that must be assimilated into corporate strategy. As internal and external market forces redefine stakeholder expectations, businesses are being pressured to take on a more meaningful role in development. Furthermore, the emergence of new challenges requires an even more holistic sense of social responsibility. The exponential rise in population, for example, is putting a strain on SSR's ability to sustain for this would mean an upsurge of demands for humanitarian assistance among the disenfranchised who are unable to access adequate support and services from the state (AIM Center for Corporate Responsibility, 2014).

Despite the fact that Davao City was hailed as the friendliest city to the micro- small-medium business sector by The Asian Institute of Management (AIM) Policy Center in 2010, there's not much literature on measuring the political commitment and sense of social responsibility among Davao City-based SMEs, especially those that are socially oriented (Biliran, 2010).

There is a growing imperative for enterprises to re-evaluate their roles in society and rethink their relationship with the community and the people who are affected by their corporate attitude and behavior either directly or indirectly. It is against these backgrounds that the researchers find it urgent to evaluate the level of political commitment and the sense of social responsibility of social entrepreneurs among the small and medium-sized social enterprises (SMSEs) operating in Davao City.

\section{Research Problem}

This study aims to find out if there exists significant relationship between levels of political commitment and sense of social responsibility among social entrepreneurs in Davao City. Specifically, this study aimed to:

1). To determine the level of political commitment among social entrepreneurs of

SMSEs in Davao City in terms of:

Political Intention and Action

Political Coordination with other Stakeholders

Public Commitment.

2). To determine the level of sense of social responsibility among social entrepreneurs of SMSEs in Davao City in terms of:

\section{Employee Relations \\ Customer Relations \\ Community Involvement \\ Social Awareness.}

3). To determine if there is significant difference in the levels of political commitment and sense of social responsibility when analyzed according to:

Sex

Type of Business Venture.

To determine the significant relationship between political commitment and sense of social responsibility among social entrepreneurs of SMSEs in Davao City?

\section{Null Hypotheses}

The null hypotheses below were tested at 0.05 level of significance.

There is no significant difference in the levels of political commitment and sense of social responsibility when analyzed according to sex and type of business ventures.

There is no significant relationship between political commitment and sense of social responsibility among social entrepreneurs in Davao City. 


\section{Research Methodology}

This study employed the non-experimental descriptive-correlation research design in investigating the research problem. The non-experimental descriptive correlation is a method used to describe the significant relationship between variables by presenting the data in quantitative descriptions without changing or manipulating the environment (Creswell, 2003). Creswell further added that this type of study is usually the best method for collecting information that will demonstrate relationships between two or more variables and describe the world as it exists.

\subsection{Research Subjects}

The respondents of the study were 47 social entrepreneurs who were currently engaged in running small and medium-sized social enterprises based in Davao City. As per the Central Limit Theorem, a sample size of thirty (30) and above is generally accepted as sufficient (Duranczyk, Loch, and Stottlemyer, 2013). The study used the snowball sampling method in choosing the respondents. This method is useful when the samples specifically required in the study are difficult to identify or when the respondents are very rare to locate (Johnson and Christensen (2014). As of the moment, the idea of social enterprise is still in its infancy stage in Davao City. The lack of standard legal concept despite the presence of initiatives makes it extremely challenging to identify them. Since identifying SMSEs requires mapping them out without any official government record, the researchers rely mainly on the referrals from social entrepreneurs to locate others like them. Table 1 shows the distribution of respondents. These respondents were chosen for they are either owners/managers of small and medium-sized social enterprises that are legally registered and located in Davao City.

Table 1. Distribution of Respondents

\begin{tabular}{lcc}
\hline \multicolumn{1}{c}{ Pex } & Number & Percentage \\
\hline Male & 16 & \\
Female & 31 & $34.04 \%$ \\
TOTAL & $\mathbf{4 7}$ & $65.96 \%$ \\
$\quad$ Type of Business Venture & & $\mathbf{1 0 0 \%}$ \\
Agriculture & 2 & \\
Health and Wellness & 5 & $4.26 \%$ \\
Food & 2 & $10.64 \%$ \\
Fashion and Accessories & 27 & $4.26 \%$ \\
Education & 1 & $57.45 \%$ \\
Retail & 3 & $2.13 \%$ \\
Manufacturing & 3 & $6.38 \%$ \\
Buy and Sell & 1 & $6.38 \%$ \\
Gift Shop & 1 & $2.13 \%$ \\
Business Services & 1 & $2.13 \%$ \\
Micro-financing & 1 & $2.13 \%$ \\
TOTAL & $\mathbf{4 7}$ & $2.13 \%$ \\
\hline
\end{tabular}

Out of 47 respondents involved in various types of business ventures, sixteen (16) respondents were males while thirty-one (31) were females. Male and female respondents constitute $34.04 \%$ and $65.96 \%$ of the sampling population respectively.

In terms of the type of business venture the respondents were involved in, 27 (57.45\%) of them were in the fashion and accessories line of business. Health and wellness came second with 5 (10.64\%) social entrepreneurs actively pursuing such venture. Retail and manufacturing had $3(6.38 \%)$ respondents each. In the food and agriculture-related ventures, 2 $(4.26 \%)$ social entrepreneurs each were identified and located. Lastly, buy and sell, gift shop, business services, and micro financing had $1(2.13 \%)$ respondent each surveyed.

\subsection{Measures}

The instrument used in this study consisted of three parts. Part one contains the personal data and it was composed of 4 items intended to gather the data of the subjects which include the following: name (optional), age (optional), sex 
(required), and type of business venture (required). Part two contains the questionnaire on political commitment was composed of 3 parts representing the indicators with a total of 15 items in the form of a checklist in which respondents were asked to check the answer they had chosen. Adapted in its modified form from The Hunger Reduction Commitment Index (HRCI), the following are the political commitment indicators: (1) political intention and action, (2) political coordination with other stakeholders, and (3) public commitment. On the other hand, the questionnaire on the sense of social responsibility was comprised of 4 parts that corresponded to its four indicators with a total of 20 items. Each indicator had 5 items or statements. Adapted in its modified form, the questionnaire was divided into categories representing the indicators which capture the dimensions of Small Enterprise Social Responsibility Inventory (SESRI) namely: customer relations, employee relations, community involvement, and social awareness. This study used 5 point likert scale.

\section{Results and Discussions}

\subsection{Level of Political Commitment among Social Entrepreneurs in Davao City}

Shown in Table 2 is the level of political commitment among social entrepreneurs in Davao City. Reflected in the table, the indicator with the highest mean score of 4.28 described as High was political intention and action. On the other hand, the indicator with the lowest mean score of 3.62, also interpreted as High was political coordination with other stakeholders. The obtained overall mean score was 3.93 with a verbal equivalent of High. This implies that the social entrepreneurs have the intent, the capacity/means to act given the opportunities and constraints, and the decisive willingness to commit to varying degrees of political involvement to influence the local policy landscape in favor of SMSEs.

In terms of political intention and action, the overall mean score was 4.28 with the verbal equivalent of High which means that apart from their intent to be politically involved, social entrepreneurs are also highly willing to concretize their political desire into feasible political actions leading to achievable policy outcomes. Under this indicator, the item about SMSEs being very important in the socio-economic development of the city obtained the highest mean score of 4.51 described as Very High. This implies that social entrepreneurs keenly believe in the meaningful and productive societal role that small and medium-sized social enterprises play in advancing the socio-economic progress in the city. The mean score of 4.51 also indicated a strong nascent intent on the part of social entrepreneurs to further advance the social gains that SMSEs already achieved by supporting advocacies in their favor. The item about social entrepreneurs employ government policies that promote SMSEs obtained the lowest mean score of 3.94 still described as High. Despite the lack of government-led initiatives to support the growth and expansion of SMSEs, the data suggest that the respondents are still likely to make use of government policies that would clearly benefit them. The results confirm the viewpoint of Brinkerhoff (2000) that political commitment has a latent quality. Political intention may not be clearly tangible in the absence of action but as soon as social entrepreneurs assess their capacity for action after carefully weighing the constraints, the intention is then articulated into action.

In terms of political coordination with other stakeholders, the overall mean was 3.62 which is High. This indicates that social entrepreneurs exhibit high level of willingness to politically coordinate with other stakeholders in order to optimize the chances of fulfilling their entrepreneurial advocacies on the political level. Looking into the data further, there are 4 items described as High although they differ on their mean scores. The item on joining efforts with .other businesses in delivering a coordinated approach to support and promote SMSEs garnered the highest mean score of 3.77 interpreted as High. This means that social entrepreneurs have the highest preference for coordinating with their fellow entrepreneurs due to shared interests. Furthermore, social entrepreneurs gravitate toward each other in one way or another because despite the diversity of their socio-economic pursuits and specializations, they all have a common denominator which includes defining what the social problems are and contextualizing the solutions agenda to address such concerns. On the other hand, the item on joining efforts with the Ruling Political Party in delivering a coordinated approach to support and promote SMSEs in Davao City had the lowest mean score of 3.49 interpreted as Moderate. The result paints a rather interesting picture of how social entrepreneurs view political coordination with the Ruling Local Party from their perspective. This would imply that compared to other stakeholders mentioned in the questionnaire, the social entrepreneurs exhibit the lowest collaborative tendencies when dealing with the Party in power.

On the whole, the data reflect that social entrepreneurs in Davao City demonstrate a high level of willingness to work alongside other societal stakeholders in achieving a more optimal policy outcome in their favor. This means social entrepreneurs are keenly aware of the need to cooperate and coordinate alongside others to create a more meaningful social impact to communities in which they serve. 
The findings confirm the view that in a democratic setting, cross-sectoral coordinated approach makes policy agenda more inclusive to all stakeholders concerned (Lintel et.al, 2011). Furthermore, it could even drive innovation on the policy level as it brings in cross-sectoral expertise in the realm of collective decision- making.

Table 2. Level of Political Commitment among Social Entrepreneurs In Davao City

\begin{tabular}{lll}
\hline INDICATORS & Mean & Description \\
\hline Political Intention and Action & 4.28 & High \\
Political Coordination with other Stakeholders & 3.62 & High \\
Public Commitment & 3.90 & High \\
OVERALL MEAN & 3.93 & High \\
\hline
\end{tabular}

While the access to influence in an institutional policy structure may not be entirely fair as in most cases, the only way to gain equitable access to policy setting is by engaging politically instead of running away from it. As the Stakeholder Theory posits that organizations cannot exist in isolation. For social entrepreneurs running the SMSEs, political coordination becomes an imperative for socially-driven business enterprises that aim to effect a constructive and desirable societal influence.

In terms of public commitment, the overall mean score was 3.90 verbally interpreted as High. This signifies that social entrepreneurs demonstrate a high level of will in expressing their commitments to certain policy preferences through public statements. The item about sharing social entrepreneurial values and skills obtained the highest mean score of 4.26 described as High. This implies that social entrepreneurs keep social entrepreneurship on a more sustainable path by transmitting the values and skills to others which in turn creates a larger pool of social entrepreneurs willing enough to take on some problems of society. The item on making public statements through various media platforms (social media, print media, TV, radio, and etc.) in support of policies that favor SMSEs had the lowest recorded mean score of 3.43 described as Moderate. This implies that while a significant portion of social entrepreneurs do convey public messages supporting SMSEs through various media platforms, a considerable number of them do not engage in such. On the whole, the overall mean score of 3.90 or High reflected a high level of public commitment among social entrepreneurs in Davao City. This means that communicating with the public is an imperative means to entrench greater understanding of SMSEs, encourage better appreciation of the role they play in society, and mobilize public support for policies that empower them. Building public support is a must-have for any social entrepreneurs. In a strategic sense, it is part of the programs and activities that actors are involved in various stages of the policymaking process (Brinkerhoff, 2000).

In summary, the findings can be explained from different theoretical perspectives. From a positivist view, political commitment empowers change- enablers to shape public opinion and redefine the policy landscape by offering innovative sustainable solutions to problems which the government could not completely solve (Santos, 2009). In addition, public choice-social choice theory explains that the dysfunctional nature of the existing institutional structures and distributive mechanisms do not often lead to equitable and sustainable social utilitarian function. This compels enterprising individuals and groups to reinvent governance and society through entrepreneurial innovations in a wide array of human activities.

\subsection{Table 3 Level of Sense of Social Responsibility among Social Entrepreneurs in Davao City}

Presented in Table 3 is the level of sense of social responsibility among social entrepreneurs in Davao City. Reflected in the table, the indicator with the highest mean score of 4.63 was customer relations described as Very High. On the other hand, the indicator with the lowest mean score of 4.20 was social awareness of the SSR concept and practice. The overall posted mean score of 4.48 interpreted as High meant that the respondents are highly engaged in various aspects of SSR. Furthermore, it appears that they have a good grasp as far as the conceptual understanding of sense of social responsibility.

In terms of employee relations, the recorded overall mean score was 4.62 interpreted as Very High. Actually, all mean scores for each item under this indicator are interpreted as Very High with varying individual figures. 
Table 3. Level of Sense of Social Responsibility among Social Entrepreneurs of SMSEs in Davao City

\begin{tabular}{lll}
\hline Indicators & Mean & Description \\
\hline Employee Relations & 4.62 & Very High \\
Customer Relations & 4.63 & Very High \\
Community Involvement & 4.46 & High \\
Social Awareness & 4.20 & High \\
OVERALL MEAN & 4.48 & High \\
\hline
\end{tabular}

This signifies that the respondents are highly socially responsible when it comes to looking after their employees' welfare. The item on ensuring that due process is observed in situations where employees breach company rules and regulations received the highest mean score of 4.70 or Very High. This implies that social entrepreneurs strongly uphold a sense of justice in the workplace in the fairest environment possible. The item on providing workers with proper and regular training garnered the lowest mean score of 4.53 interpreted as Very High. This tells us that the respondents keenly ensured that employees are properly trained to get the jobs done more efficiently and effectively.

In summary, the overall mean score of 4.62 or Very High implied that social entrepreneurs put a very high level of importance on employee relations. Employees, after all, are mostly at the forefront of customer engagement. The firm interacts with the target market mainly through their employees. The results confirm Mishra's and Suar's (2010) argument that business employee relations constitute the most important issue as far as sense of social responsibility (SSR) is concerned.

In terms of customer relations, the overall mean score was 4.63 described as Very High. All mean scores for each item under this indicator are described as Very High although their individual figures vary. This means that the respondents have an excellent relationship with their customers. The item on committing oneself to fair trading practices obtained the highest score of 4.68 or Very High. This suggests that the social entrepreneurs in this study highly observe ethical and legal business conduct. Two items garnered the lowest posted mean score of 4.60 interpreted as Very High. The item on suggesting alternative options to customers when the company does not have the products/services that customers want garnered a mean score of 4.60 or Very High. This means that social entrepreneurs walk an extra mile to add value to customer experience even to the point of suggesting alternative options to give the customers what they really want. The item on putting customer satisfaction above finance and human resources issues had a mean score of 4.60 or Very High. This means that for most respondents, if not all, customer satisfaction is one of the most important priorities to fulfill. Customers, after all, are the lifeblood that keeps the cash flowing in; thereby sustaining the business. In summary, the overall mean score of 4.63 described as Very High implied that the respondents place a huge importance in keeping customers happy and satisfied by continuously creating better value for them. The findings are supported by the customer-centric view of SSR. A strategic SSR plan of any enterprise should continuously create better economic value for customers for every product sold and for every service rendered.

In terms of community involvement, the overall mean score was 4.46 interpreted as High. Two out of five items were Very High while the rest were interpreted as High. The high mean score suggests that the respondents are sensitive to community issues. On giving priority to vulnerable groups such as children, disabled people, and the elderly, the mean score was the highest at 4.62 or Very High. This suggests that social entrepreneurs observe great care when dealing with vulnerable groups. The item on allowing employees to use company time for community issues had the lowest posted mean score of 4.32 or High. This suggests that the social entrepreneurs surveyed in this study do allow giving away a certain portion of valuable company time to participate in activities relevant to community issues. On the whole, the overall score of 4.46 or High implied that social entrepreneurs are highly responsive and sensitive to concerns and issues that relate to the community. Businesses already perform an important role which is wealth

creation. However, social enterprises add more social value to this traditional economic role by incorporating community-oriented goals and objectives alongside their conventional economic function such as providing resources for community disaster relief programs and education (Afrane\& Adjei-Poku,2013). This is furthered by the fact that the sustainability of enterprises (profit-oriented or otherwise) is also largely affected by the stability of the communities where these businesses are operating (Coutsoukis, 2002).

In terms of social awareness, the overall mean score was 4.20 which had a verbal descriptive equivalent of High. All mean scores for each item under this indicator are described as High although scores may vary in terms of individual figures. The high mean score implies that most, if not all, respondents have a high level of understanding of the SSR as a concept. For the item on practicing the sense of social responsibility, the mean score recorded the highest at 4.34 
described as High. This signifies high involvement in SSR-related endeavors by the social entrepreneurs. On practicing SSR to enhance the image of the company, the mean score posted the lowest at 4.11 still described as High. This indicates that it's not just purely altruistic motives that drives the respondents to practice SSR. The score implies that they are also incentivized to do it because it enhances company image (and maybe prestige). On the whole, the overall rating of 4.20 or High showed that social entrepreneurs are highly engaged in activities that constitute SSR. The results show that SSR is not just an appeasement tool to support altruistic endeavors that benefit third party stakeholders. On a pragmatic level, it also serves another role of creating value that directly benefits the direct stakeholders such as the shareholders themselves (Pirnea, Olaru, \&Angheluta, 2012).

In totality, all the findings confirm the Stakeholder Theory which argues that businesses do not exist and operate in isolation. Apart from their shareholders, their activities also impact external stakeholders that are affected by their operations. Thus, firms (whether for profit-oriented or otherwise) also need to perform that would satisfy their societal obligations other than their shareholders (Freeman and McVea,

2001).

\subsection{Significance of the Difference}

Presented in Tables 4.3 is the significance of the difference of political commitment and sense of social responsibility when analyzed according to sex and type of business venture. Looking into the data under political commitment, the $\mathrm{t}$-value was at 0.411 while the $\mathrm{p}$-value was at 0.525 when grouped according to sex. Hence, no significant difference exists. This means that sex is not an influencing factor that affects the level of political commitment among social entrepreneurs of SMSEs.

When analyzed according to type of business venture, the f-value posts at 2.706 while the p-value records 0.018 indicating that a significant difference exists. This is probably due to the fact that a large portion of social entrepreneurs covered in the survey are running SMSEs that specialize in indigenous tribal arts and fashion, accessories, and crafts. Their social enterprises mainly create market avenues for Lumad handiworks and reinvesting a part of their profits to sustain cottage industries in the indigenous communities.

On the other hand, the data under the sense of social responsibility showed that the t-value is at 1.063 while the $\mathrm{p}$-value is at 0.308 when grouped according to sex. When analyzed according to type of business venture, the t-value posts 1.130 while the $\mathrm{p}$-value records 0.366 . As the numbers indicate, there is no significant difference in the sense of social responsibility when analyzed according sex and type of business venture. This means that sex and type of business venture are not crucial factors that affect the respondent's level of SSR.

Table 4.3 Significance of the Difference of Political Commitment and Sense of Social Responsibility among Social Entrepreneurs in Davao City

\begin{tabular}{lllll}
\hline Variables & & t-value & p-value & Interpretation \\
\hline $\begin{array}{l}\text { Political } \\
\text { Commitment }\end{array}$ & $\begin{array}{l}\text { Sex } \\
\text { Type of Business } \\
\text { Ventures }\end{array}$ & 0.411 & 0.525 & Not Significant \\
$\begin{array}{l}\text { Sense of Social } \\
\text { Responsibility }\end{array}$ & $\begin{array}{l}\text { Sex } \\
\text { Type of Business } \\
\text { Ventures }\end{array}$ & $2.706^{*}$ & 0.018 & Significant \\
\hline
\end{tabular}

*f-value

\subsection{Correlations between Measures}

Shown in Table 4.4 is the significance of the relationship between political commitment and sense of social responsibility among social entrepreneurs in Davao City. The results are as follows: the r-value is 0.656, the $\mathrm{r}$-squared value was $43.03 \%$, and the p-value is 0.000 . Given these data, a significant relationship exists between political commitment and sense of social responsibility. The sense of social responsibility is in fact a highly observed characteristic among social entrepreneurs since they are chiefly concerned with creating innovative sustainable entrepreneurial solutions when markets and governments fail (Santos, 2009). With their constant exposure to socio-economic problems and their continuing efforts to find a way to address them, social entrepreneurs already possess that Schumpeterian entrepreneurial willpower to force change on society (Abdu and Johansson, 2009). The challenge now is how to translate that willpower into the political sphere. Clearly, many of the issues and concerns that 
social entrepreneurs are dealing are well within the realm of the political economy which touches the domain of public policy. While some social entrepreneurs have already been politically involved, there is much work to do in terms of stimulating the residual political intent of the less politically involved and nurturing it to build a strong political commitment across the social enterprise sector. A political convergence of social entrepreneurs with multi-sectoral expertise shaped by knowledge and experience could do to a failing government what a computer technician does to a failing computer: system reformat.

Table 6. Significance of the Relationship between Political Commitment and Sense of Social Responsibility among Social Entrepreneurs in Davao City

\begin{tabular}{llllll}
\hline Variable & r-value & Interpretation & r-squared & p-value & $\begin{array}{c}\text { Decision } \\
\text { an un }\end{array}$ \\
\hline $\begin{array}{l}\text { Political } \\
\text { Commitment vs }\end{array}$ & 0.656 & $\begin{array}{l}\text { Moderately } \\
\text { Significant }\end{array}$ & $43.03 \%$ & 0.000 & Significant \\
$\begin{array}{l}\text { Sense of Social } \\
\text { Responsibility }\end{array}$ & & & & \\
\hline
\end{tabular}

\section{Conclusions}

In the light of the findings derived from this study, the following conclusions are drawn:

The level of political commitment described as High suggests that the respondents have the intent, the capacity and means to act given the opportunities and constraints, and the decisive willingness to commit to varying degrees of political involvement to influence the local policy landscape in favor of SMSEs.

The level of sense of social responsibility interpreted as High implies respondents are highly engaged in various aspects of SSR. In addition, they seem to have a good grasp and understanding of the nature of SSR both as a concept and corporate practice.

There is no significant difference in the level of political commitment and sense of social responsibility when analyzed according to sex. This means that sex is a not a crucial factor that affects social entrepreneurs' political commitment and sense of social responsibility.

There is a significant difference in terms of political commitment when grouped according to type of business venture. This is probably attributed to the fact that a large portion of the respondents covered in the survey are engaged in fashion and accessories business that directly benefits the Lumad or indigenous tribal communities. On another note, no significant difference exists in terms of sense of social responsibility. Regardless of the nature of their business activity, social entrepreneurs are socially-oriented individuals imbued with a strong sense of mission to make a difference by way of introducing innovative entrepreneurial solutions to the pressing needs of society.

There is a significant relationship between the level of political commitment and the level of sense of social responsibility. This means that social entrepreneurs have the inclination to be actively involved in the political processes that affect the social enterprise sector. This correlation is probably due to the fact that social entrepreneurs are engaged in finding ways to address socio-economic problems when the governments and markets fail.

\section{Recommendations}

On the basis of these findings and conclusion the following recommendations are presented.

\subsection{Department of Trade and Industry.}

The lack of legal definition of what constitutes a social enterprise is a big institutional hindrance that prevents social enterprises from truly taking off especially in places where they are badly needed. Compared to other countries like the UK or South Korea, the Philippine government doesn't seem to have an explicit role in facilitating the development and growth of Social Enterprises in the country. While the Philippine Social Enterprise Bill is still awaiting legislative approval, which may take a long time, the Department of Trade and Industry should nevertheless develop government capacity in action to empower existing social enterprise initiatives such as:

Consolidating and streamlining all existing government initiatives into a coherent set of programs and incentives to help develop social enterprises.

Entering into a collaborative agreement with the private sector alongside local government units to create a social enterprise zones or hubs across the country. 


\subsection{Mindanao Development Authority.}

As the institution tasked with formulating strategic development plans for Mindanao, the Mindanao Development Authority should spearhead in institutionalizing a regular cross-sectoral engagement of investors, social entrepreneurs, think tanks, socio-civic organizations, and policymakers and develop a permanent communication structure for greater coordinated action between different stakeholders to produce a concrete roadmap for social innovation involving social enterprises within the much bigger strategic development plan that the institution produces.

\subsection{City Government of Davao}

The City Government of Davao should start a localized initiative to promote the development and growth of social enterprises by coordinating with the social enterprise sector in the city. It should start by initiating a city-wide mapping out of these organizations and establishing a social enterprise directory. If possible, the City government could a create a local adhoc institute (in strategic partnership with DTI and Mindanao Development Authority) dedicated to building long-term initiatives to make social enterprise an integral part of Davao City's own effort to seek entrepreneurial solutions to various problems of society.

\subsection{Social Entrepreneurs of SMSEs.}

Social entrepreneurs play a vital role in introducing innovation to governance structures. However, there seems to be no consolidated and unified effort among social entrepreneurs in the country to influence a more conducive policy environment for social enterprises to develop and grow. Building political commitment to effect a change in the policy landscape at least in the local level is best achieved when social enterprises aggregate and form a stronger and more unified sector to lobby for policies that favor the development of a sustainable and inclusive social economy.

\subsection{University of Mindanao Political Science Discipline}

The Political Science Discipline should encourage more scholarly pursuits among students and even teachers alike to explore entrepreneurial innovations in governance outside the realm of conventional government structures.

\subsection{Other Researchers}

Future researchers wanting to do a relevant research in subject area might consider doing case studies on successful social enterprises in Davao City or elsewhere and see how their success stories could inspire even become a source of valuable lessons of social innovation.

\section{Acknowledgment}

This work would not have been possible without the underlying support of the people around us. Our heartfelt gratitude goes to everyone who has relentless belief in our capabilities to the completion of this undertaking. To University of Mindanao Research and Publication Center for the support to this endeavor. To Dr. Gerlieta S. Ruiz, Dr. Khristine Marie Concepcion, Dr. Evangeline M. Guinto, and Prof. Luzviminda T. Orilla for encouraging us in disseminating the research findings through publication.

\section{References}

Abdu, A., \& Johansson, E. (2009). Social Entrepreneurship - A Case Study of SIFE Umeå University. Retrieved June 29, 2015 from http://www.diva- portal.org/smash/get/diva2:279268/FULLTEXT01.pdf.

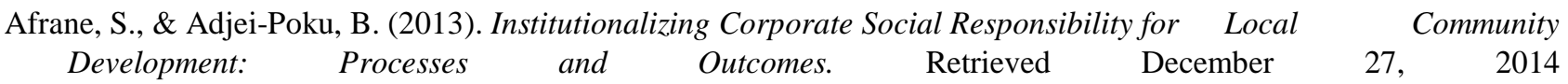
http://search.proquest.com/docview/1462439430/CEF281A0A92440F6PQ/3? accountid=31259.

AIM RVR Center for Corporate Responsibility (2014). Corporate Social Responsibility in the Philippines. http://csrbookshelf.bcyfoundation.org/wpcontent/uploads/2014/09/philippines_05_hrd_csr.pdf.

Biliran, R. (2010). Davao City helps SMEs with financing difficulties. Retrieved January 5, 2015 from http://www.mindanews.com/business/2010/07/24/davao-city-helps- smes- with- financing-difficulties/.

Brinkerhoff, D. (2000). Assessing Political Will for Anti-corruption Efforts: An Analytical Framework. Retrieved January 16, 2015 from http://info.worldbank.org/etools/docs/library/108384/session4I.pdf.

Camposano, J. (2014). SMEs seen as major economic growth driver. The Philippine Star. Retrieved January 4, 2015 from http://www.philstar.com/business-usual/2014/01/20/1280682/smes-seen- major-economic-growth-driver>.

Coutsoukis, P. (2002). Strategic community involvement: The inner thread of corporate citizenship. http://search.proquest.com/docview/304789847/CEF281A0A92440F6PQ/26? accountid=31259.

Creswell, J. (2003). Research Design: Qualitative, Quantitative, and Mixed Methods Approaches. http://isites.harvard.edu/fs/docs/icb.topic1334586.files/2003_Creswell_A\%20F ramework\%20for\%20Design.pdf. 
Duranczyk, I. M., Loch, S., \& Stottlemyer, J. (2013). Central Limit Theorem: Assumptions and Conditions. http://legacy.cnx.org/content/m46217/latest/?collection=col11521/latest.

Freeman, R. E., \& McVea, J. (2001) A Stakeholder Approach to Strategic Management. Darden Business School Working Paper. Retrieved January 15, 2015 from http://dx.doi.org/10.2139/ssrn.263511.

Johnson, R. B., \& Christensen, L. (2014). Educational Research: Quantitative, Qualitative and Mixed Approaches. $5^{\text {th }}$ ed. Los Angeles: SAGE Publications, Inc.

Lintelo, D., Haddad, L., Leavy, J., Masset, E., \& Stanley, A. (2011). Measuring theCommitment to Reduce Hunger: The Hunger Reduction Commitment Index. Retrieved on: January 16, 2015 from

http://www.hancindex.org/wp-content/uploads/2011/09/hrci-final-report-for- web-draft.pdf.

Mishra, S., \& Suar, D. (2010). Do stakeholder management strategy and salience influence corporate social responsibility in Indian companies?. Retrieved January 6, 2015 from http://search.proquest.com/docview/1012103428/31EEF46BFC9E4505PQ/5? accountid=31259.

Pirnea, I, Olaru, M., \& Angheluta, T. (2012). Study on the Impact on Promoting Social Responsibility in Business Performance for SMEs. Retrieved December 30, 2015 from http://search.proquest.com/docview/1117313971/4F6E9095E3D41B2PQ/17? accountid=31259.

Post, L., Salmon, C., \& Raile A. N. W. (2008). Using Public Will to Secure Political Will. Retrieved January 16, 2015 from http://siteresources.worldbank.org/EXTGOVACC/Resources/GovReform_ebo ok.pdf.

Santos, F. (2009). A Positive Theory of Social Entrepreneurship. INSEAD 2009. Retrieved on June 27, 2015 from http://www.insead.edu/facultyresearch/centres/social_entrepreneurship/resear ch_resources/documents/2009-23.pdf.

Spear, R., Cornforth, C., \& Aiken, M. (2009).The governance challenges of social enterprises: evidence from a UK empirical study. Retrieved January 5, 2015 from http://oro.open.ac.uk/15849/1/Annals_Governance_of_soc_ent_ Feb09_Revd-CC.pdf.

Thornton, J., \& Byrd, J. (2013). Social Responsibility and the Small Business. http://search.proquest.com/docview/1368593828/4F6E9095E3D41B2PQ/16? accountid=31259.

Zastrow, C., \& Bowker, L. (1984). Social Problems: Issues and Solutions. http://www.jstor.org/stable/23252841.

\section{(cc) EY}

This work is licensed under a Creative Commons Attribution 3.0 License. 